\title{
Comparison of systemic right ventricular function in transposition of the great arteries after atrial switch and congenitally corrected transposition of the great arteries
}

Michael Morcos ${ }^{1 *}$, Philip J Kilner ${ }^{2}$, David J Sahn ${ }^{3}$, Willem Helbing ${ }^{4}$, Harold Litt ${ }^{5}$, Emanuela Valsangiacomo-Buechel ${ }^{6}$, Florence Sheehan ${ }^{7}$

From 19th Annual SCMR Scientific Sessions

Los Angeles, CA, USA. 27-30 January 2016

\section{Background}

In patients with transposition of the great arteries corrected by interatrial baffle (TGA) and those with congenitally corrected transposition of the great arteries (ccTGA) the right ventricle (RV) is subjected to systemic pressures and fails prematurely. We sought to further characterize the geometric, global and regional functional differences between these two groups.

\section{Methods}

Using cardiac magnetic resonance imaging (MRI) the RV was reconstructed from manually traced borders of the ventricles, valves, and other anatomic landmarks of 25 patients with TGA, 17 patients with ccTGA, and 9 normal subjects. Global function was assessed by calculating RV ejection fraction (RVEF) as well as tricuspid annular plane systolic excursion (TAPSE). Regional wall motion was assessed in ten anatomic territories of the RV using the centersurface method.

\section{Results}

The RV in TGA and ccTGA was more dilated, rounder, and had reduced global and regional function when compared to the normal RV. RVEF correlated better with transverse than longitudinal contraction. When the subgroups were compared, TGA patients had lower RVEF than ccTGA $(29.7 \pm 6.5 \%$ vs. $34.7 \pm 7.4 \%, \mathrm{p}=$ $0.02)$, lower normalized TAPSE $(0.097 \pm 0.035$ vs. 0.177 $\pm 0.044, \mathrm{p}<0.01)$, and weaker basal segment contraction

${ }^{1}$ Department of Medicine, University of Washington, Seattle, WA, USA Full list of author information is available at the end of the article (image 1 and 2). However RV shape was similar in the two groups, and there was only a tendency towards a more dilated TGA RV (end diastolic volume index 145 \pm 35 vs. $132 \pm 41 \mathrm{~mL} / \mathrm{m}^{2}$ in ccTGA, $\mathrm{p}=0.09$ ).

\section{Conclusions}

As a result of the hemodynamic overload, the RVs in both TGA and ccTGA are dilated and rounder than normal. The weak correlation of RVEF with TAPSE may be attributable to increased reliance on transverse shortening. Furthermore, TGA and ccTGA RVs have distinct

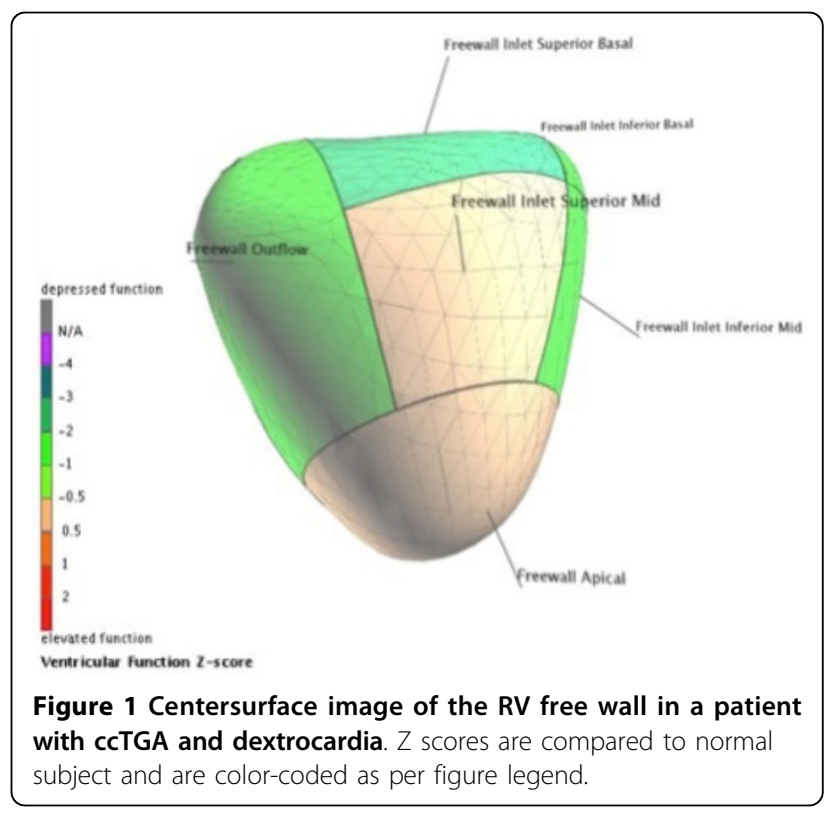




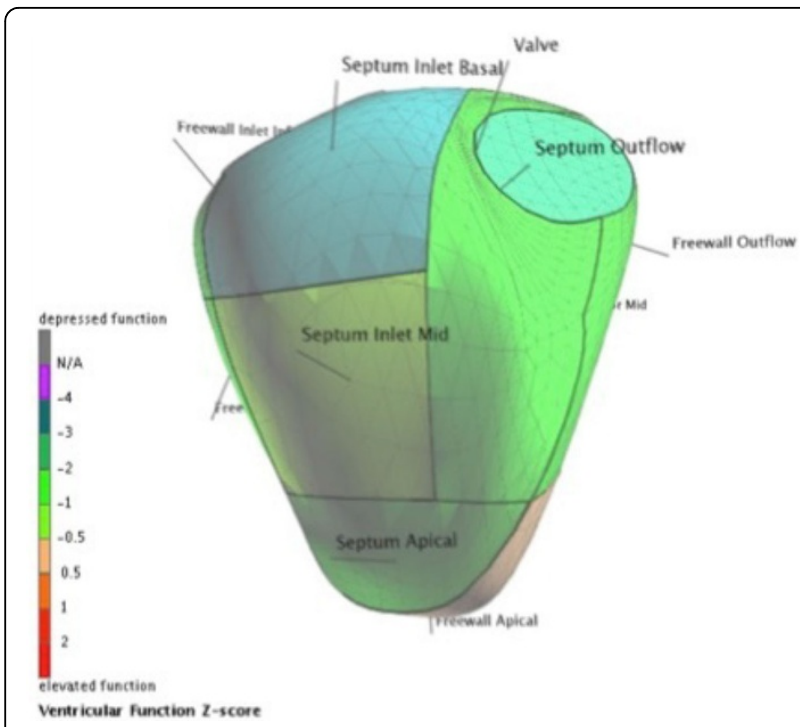

Figure 2 Centersurface image of the RV septal wall in a patient with ccTGA and dextrocardia. Z scores are compared to normal subject and are color-coded as per figure legend.

wall motion and remodeling patterns with the added insult of reduced basilar function in the TGA RV. The possibility of basilar scarring, either attributable to congenital differences between the two patient populations, the interatrial baffle, or the surgery itself, may account for the morphological and functional differences seen between the two groups with systemic RVs.

\section{Authors' details}

${ }^{1}$ Department of Medicine, University of Washington, Seattle, WA, USA. ${ }^{2}$ Royal Brompton Hospital, London, United Kingdom. ${ }^{3}$ Oregon Health and Science University, Portland, OR, USA. ${ }^{4}$ Department of Pediatrics (Division of Cardiology) and Radiology, Erasmus Medical Center Sophia Children's Hospital, Rotterdam, Netherlands. ${ }^{5}$ University of Pennsylvania, Philadelphia, PA, USA. ${ }^{6}$ University of CHildren's Hospital, Zurich, Switzerland. ${ }^{7}$ Department of Cardiology, University of Washington, Seattle, WA, USA.

Published: 27 January 2016
doi:10.1186/1532-429X-18-S1-P152

Cite this article as: Morcos et al: Comparison of systemic right ventricular function in transposition of the great arteries after atrial switch and congenitally corrected transposition of the great arteries. Journal of Cardiovascular Magnetic Resonance 2016 18(Suppl 1):P152.

\section{Submit your next manuscript to BioMed Central} and take full advantage of:

- Convenient online submission

- Thorough peer review

- No space constraints or color figure charges

- Immediate publication on acceptance

- Inclusion in PubMed, CAS, Scopus and Google Scholar

- Research which is freely available for redistribution

Submit your manuscript at www.biomedcentral.com/submit 